\title{
Characteristics of the Contrast Enema Do Not Predict an Effective Bowel Management Regimen for Patients with Constipation or Fecal Incontinence
}

\author{
Jordan Huber ${ }^{1}$, Douglas C. Barnhart ${ }^{2}$, Shawn Liechty ${ }^{1}$, Sarah Zobell ${ }^{2}$, Michael D. Rollins ${ }^{3}$ \\ 1. School of Medicine, University of Utah School of Medicine 2. Division of Pediatric Surgery, Primary \\ Children's Medical Center 3. Department of Surgery, Primary Children's Medical Center
}

$\square$ Corresponding author: Jordan Huber, jordan.huber@hsc.utah.edu

Disclosures can be found in Additional Information at the end of the article

\section{Abstract}

Background: A bowel management program using large volume enemas may be required for children with anorectal malformations (ARM), Hirschsprung's disease (HD), severe medically refractive idiopathic constipation (IC), and other conditions. A pretreatment contrast enema is often obtained. We sought to determine if the contrast enema findings could predict a final enema regimen.

Methods: A retrospective review was performed at a tertiary care children's hospital from 2011 to 2014 to identify patients treated with enemas in our bowel management program. Patient characteristics, contrast enema findings (including volume to completely fill the colon), and final enema regimen were collected.

Results: Eighty-three patients were identified (37 ARM, 7 HD, 34 IC, and 5 other). Age ranged from 10 months to 24 years, and weight ranged from $6.21 \mathrm{~kg}$ to $95.6 \mathrm{~kg}$ at the time bowel management was initiated. Linear regression showed contrast enema volume was of limited value in predicting effective therapeutic saline enema volume $\left(\mathrm{R}^{2}=0.21\right)$. The addition of diagnosis, colon dilation, and contrast retention on plain $\mathrm{x}$-ray the day after the contrast enema moderately improved the predictive ability of the contrast enema $\left(R^{2}=0.35\right)$. Median final effective enema volume was $22 \mathrm{~mL} / \mathrm{kg}$ (range: 5 - $48 \mathrm{~mL} / \mathrm{kg}$ ).

Conclusions: We were unable to demonstrate a correlation with contrast enema findings and the effective enema volume. However, no patient required a daily enema volume greater than 48 $\mathrm{mL} / \mathrm{kg}$ to stay clean.

Received 03/10/2016

Review began 03/11/2016

Review ended 08/10/2016

Published 08/23/2016

C Copyright 2016

Huber et al. This is an open access article distributed under the terms of the Creative Commons Attribution License CC-BY 3.0., which permits unrestricted use, distribution, and reproduction in any medium, provided the original author and source are credited.
Categories: Pediatrics, Pediatric Surgery, Gastroenterology

Keywords: bowel management, fecal incontinence, constipation, hirschsprung's disease, anorectal malformations, idiopathic constipation, contrast enema

\section{Introduction}

Children who have undergone surgery for Hirschsprung's disease (HD), anorectal malformations (ARM), and sacrococcygeal teratomas (SCT), or those who have severe medically refractive idiopathic constipation (IC) or spine or spinal cord abnormalities may suffer from fecal incontinence or constipation [1-4]. An individualized and comprehensive bowel 
management program is often required in order to keep the patient clean and in normal underwear [5]. Large-volume saline enemas are one of the treatment modalities used for bowel management with the goal of mechanically emptying the colon daily to avoid fecal accidents.

A pretreatment contrast enema is obtained at the start of bowel management to gain information regarding the diameter and length of the colon, stool burden, and provide catharsis. Providers may then use these findings to estimate the starting enema volume. During the initial week of bowel management, the patient's clinical and radiographic responses to the enema are assessed daily. In most cases, the starting enema regimen is changed multiple times until an effective enema is discovered by trial and error. The treatment plan is considered successful when the abdominal radiograph is clear of stool in the rectum and left colon and the child has had no soiling.

Finding an effective enema regimen can be frustrating for the patient, the family, and the treating team. The bowel management program is very time-consuming, which may become extended if it is being conducted by a sole provider. The aim of this study was to determine if the contrast enema findings could predict a final enema regimen in order to simplify the trial and error process of bowel management.

\section{Materials And Methods}

A retrospective review was conducted at our tertiary care children's hospital from 2011 to 2014 with IRB approval from the University of Utah, approval \#74392. Waiver of consent was obtained from IRB for this retrospective review. Children enrolled in the bowel management program at our colorectal center were identified. Patients managed with enemas were selected for further review. Large-volume saline enemas were selected on an individual basis to manage medically refractive constipation, fecal incontinence, and pseudo-incontinence. Patient characteristics included diagnosis, age, and weight at initiation of bowel management. Radiographic observations included colonic motility, which was inferred from retained contrast on follow-up x-ray the day after the contrast enema, redundancy and dilation of the colon, and contrast volume required to fill the entire colon during the study. The colon was characterized as non-dilated, dilated rectum, rectosigmoid dilation, or global dilation (Figure 1). For analysis, patients with rectal dilation were combined with the rectosigmoid dilation group. Treatment was successful if the abdominal radiograph was clear of stool in the rectum and left colon, and the child had no soiling within one week of starting the bowel management program. Complete records, including the final enema regimen with appropriate follow-up, were available for 94 patients. 


\section{Cureus}
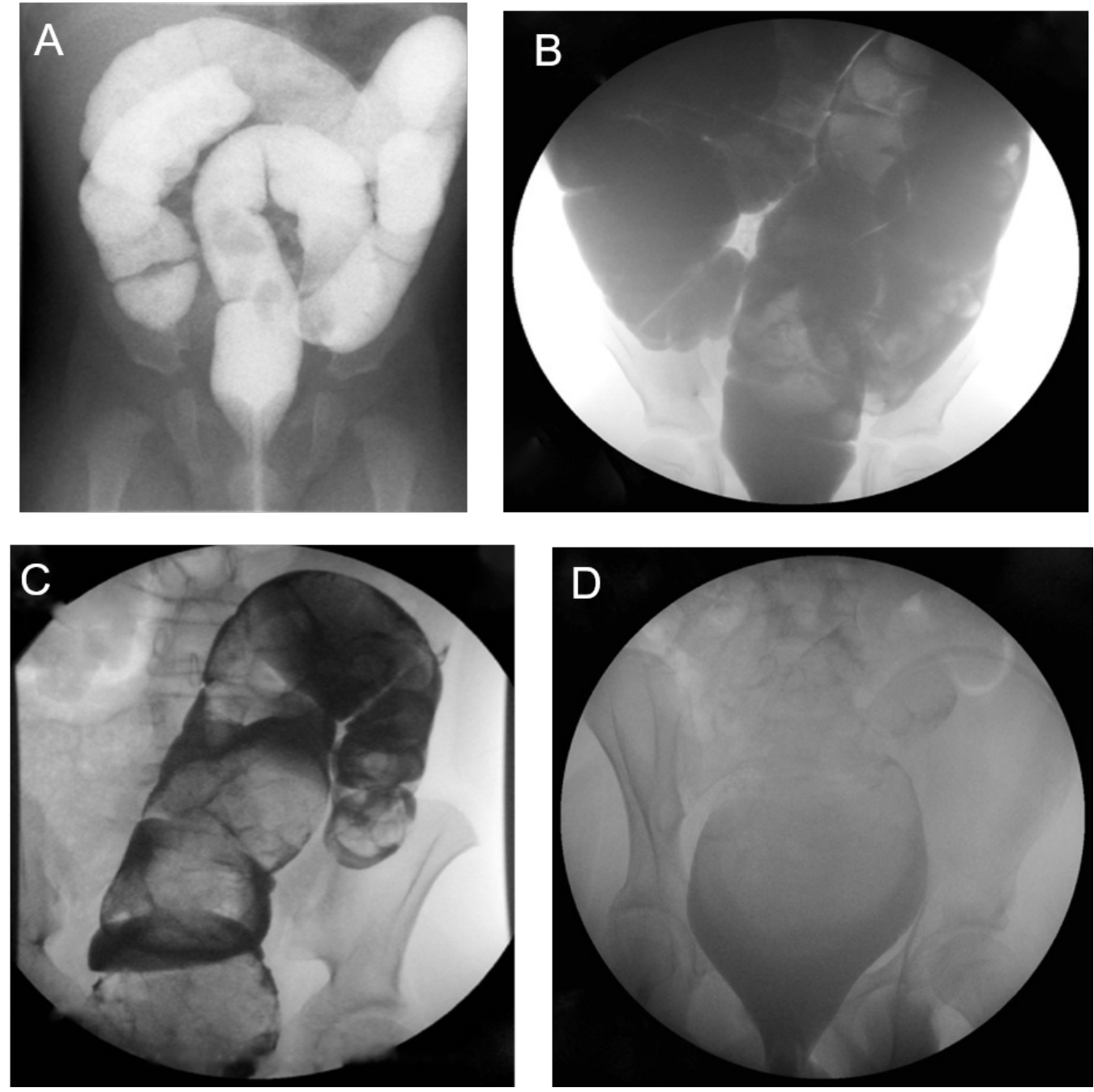

\section{FIGURE 1: Contrast Enema Findings}

$\mathrm{A}=$ normal caliber, non-dilated colon; $\mathrm{B}=$ global dilation; $\mathrm{C}=$ rectosigmoid dilation; $\mathrm{D}=$ rectal dilation.

Descriptive statistics were performed to summarize patient characteristics and enema findings. Contrast enema volume to completely fill the colon was assessed for its ability to predict the final effective therapeutic enema volume. This was done using linear regression with using SAS 9.2. Models were evaluated to examine both total contrast volume $(\mathrm{mL})$ and contrast volume by weight $(\mathrm{mL} / \mathrm{kg})$. Additional models were created including diagnosis, colon dilation, and contrast retention on plain $\mathrm{x}$-ray the day after the contrast enema. $\mathrm{R}^{2}$ was used to assess predictive values of the models.

\section{Results}

Ninety-four patients with complete records and follow-up were identified. Eight patients were non-compliant with the program, and three patients were unsuccessful (88\% success rate). Age at initiation of bowel management for the 83 patients ranged from 10 months to 24 years, and males comprised $57 \%$ of the study group. Diagnoses included anorectal malformation (37), Hirschsprung's disease (7), idiopathic constipation (34), sacrococcygeal teratoma (1), and spina bifida (4). The level of aganglionosis for patients with Hirschsprung disease and ARM types are 


\section{Cureus}

listed in Table 1.

\begin{tabular}{|c|c|c|c|}
\hline Hirschsprung Level & \# of Patients & ARM Type & \# of Patients \\
\hline Rectum & 2 & Cloaca & 4 \\
\hline Rectosigmoid & 3 & Bladder Neck Fistula & 3 \\
\hline Sigmoid & 2 & Perineal Fistula & 4 \\
\hline \multirow[t]{8}{*}{ Total } & 7 & Rectal Atresia & 3 \\
\hline & & Rectal Stenosis & 2 \\
\hline & & Rectoprostatic Fistula & 4 \\
\hline & & Rectovaginal Fistula & 7 \\
\hline & & Rectovestibular Fistula & 7 \\
\hline & & Rectourethral Bulbar Fistula & 2 \\
\hline & & Unknown & 1 \\
\hline & & Total & 37 \\
\hline
\end{tabular}

\section{TABLE 1: Hirschsprung's Disease Level and Anorectal Malformation Type}

Fifty-four percent of the patients were felt to have colonic hypomotility based on radiographic imaging. Contrast enema volumes (mL) ranged from 50 to 1500 for patients weighing < $20 \mathrm{~kg}$; 150 to 2100 for patients $20 \mathrm{~kg}$ to $50 \mathrm{~kg}$; 500 to 3300 for those weighing > $50 \mathrm{~kg}$. Median volume of contrast to fill the colon was $38 \mathrm{~mL} / \mathrm{kg}$ (range: $4-87 \mathrm{~mL} / \mathrm{kg}$ ). Patterns of colonic dilation are summarized in Table 2 . 


\section{Cureus}

\begin{tabular}{|c|c|c|c|c|}
\hline Diagnosis & Non-Dilated & Rectosigmoid Dilation & Global Dilation & Total \\
\hline ARM & 23 & 14 & 0 & 37 \\
\hline HD & 5 & 1 & 1 & $r$ \\
\hline IC & 22 & 11 & 1 & 34 \\
\hline Spina bifida & 3 & 1 & 0 & 4 \\
\hline SCT & 0 & 1 & 0 & 1 \\
\hline Total & 53 & 28 & 2 & 83 \\
\hline
\end{tabular}

\section{TABLE 2: Character of the Colon on Contrast Enemas}

ARM = Anorectal Malformation, HD = Hirschsprung's Disease, IC = Idiopathic Constipation, SCT = Sacralcoccygeal Teratoma Rectosigmoid dilation includes patients with rectal dilation and megarectum.

The final effective saline enema volume $(\mathrm{mL})$ ranged from 200 to 600 for patients $<20 \mathrm{~kg}$ (median: $500 \mathrm{~mL}$ ), 300 to 1000 for $20 \mathrm{~kg}$ to $50 \mathrm{~kg}$ (median: $600 \mathrm{~mL}$ ), and 500 to $1000 \mathrm{for}>50 \mathrm{~kg}$ (median: $675 \mathrm{~mL}$ ). Median final effective enema volume was $22 \mathrm{~mL} / \mathrm{kg}$ (range: $5-48 \mathrm{~mL} / \mathrm{kg}$ ). The addition of glycerin or castile soap to the enema was variable. Linear regression demonstrated that the contrast enema volume was of limited value in predicting the final effective saline enema volume $\left(\mathrm{R}^{2}=0.21\right)$. The addition of patient diagnosis, the pattern of colonic dilation, and presumed hypomotility moderately improved the predictive ability of the contrast volume on the therapeutic enema volume $\mathrm{R}^{2}=0.35$ ).

The overall success rate was $88 \%$. The median length of time to determine the effective enema regimen was six days with an interquartile range of three days. The median length of follow-up was 20 months with an interquartile range of 28 months.

\section{Discussion}

Successful bowel management is dependent on finding an effective enema volume to cause prompt and complete evacuation of the distal colon. This is typically done empirically with ongoing adjustments to identify the correct volume. If the final volume could be predicted by contrast enema characteristics, it is possible that the final effective volume could be determined more quickly using fewer resources and causing less frustration for patients and families. Unfortunately, we were not able to demonstrate this. Rather, contrast enema results (volume to fill the colon and secondary characteristics) accounted for only $35 \%$ of the variability seen in the final effective enema volumes at one week. While the contrast enema was not predictive of the effective enema volume at the end of the bowel management week, we did not examine the ability of the contrast enema findings to predict the effective enema volume past one week.

This retrospective study is the first providing data on the relationship between pretreatment contrast enema findings and the therapeutic enema volume used for bowel management. A management algorithm for fecal incontinence in patients with a history of anorectal malformation, Hirschsprung's disease, or spina bifida using large volume enemas has been previously reported [5]. However, the authors recommend a saline volume that ranges widely. Furthermore, the findings of the contrast enema were not used to guide enema therapy in that 
study. Other studies in patients with varying diagnoses recommend enemas of $100 \mathrm{~mL}-200 \mathrm{~mL}$. It has been recommended that individuals who have a non-dilated colon and diarrhea receive a lower volume than individuals with a dilated colon and constipation [2, 5-7]. Another recommendation has been made to start patients at a volume of $500 \mathrm{~mL}$ for incontinence and increase the volume up to $1000 \mathrm{~mL}$, if necessary [4].

An important finding in our study is that no patient required a daily enema volume greater than $1000 \mathrm{~mL}$ to stay clean and most required much less. As might be expected, we found a trend toward larger saline enema volumes in larger patients. Unexpectedly, we found that the volume of contrast used for the contrast enema did not predict the final therapeutic saline enema volume. Furthermore, including the patient's diagnosis, the pattern of colonic dilation and motility did not improve the predictive ability of the contrast enema volume in determining an effective bowel management regimen. We generally start patients $\leqslant 30 \mathrm{~kg}$ on a saline enema volume of $20 \mathrm{~mL} / \mathrm{kg}$ and add irritants (soap) as needed. For patients $>30 \mathrm{~kg}$, we will arbitrarily start at $600 \mathrm{~mL}$ of saline. The average therapeutic saline enema in our entire cohort was 23 $\mathrm{mL} / \mathrm{kg}$. The therapeutic saline volume for the majority of our patients $>20 \mathrm{~kg}$ was $600 \mathrm{~mL}$.

Bowel management can be difficult to achieve in individuals with HD, ARM, SCT, and IC. Enemas are often used to help maintain continence. In our bowel management program, we had an $88 \%$ success rate out of 94 patients in determining the therapeutic saline enema volume. It can take substantial time and resources to determine the therapeutic enema volume. It may also be frustrating for patients and families. The aim of this study was to provide guidelines to reduce the time it takes to determine an effective enema.

Limitations of this study include the retrospective nature and the $8 \%$ non-compliance rate. One might argue that our patients with Hirschsprung's disease and ARMs with a good prognosis for bowel control (perineal fistula, vestibular fistula, rectal atresia, or urethral fistula) did not need enemas for bowel management. While it is our goal to manage constipation in these patients with stimulant laxatives, we will initiate enema therapy in patients who have never been toilet trained or if the rectum is severely dilated. A laxative trial is then attempted biannually or annually as desired by the patient and family. Finally, we did not examine the predictive value of the contrast enema in our patients who require laxatives for the management of severe constipation.

\section{Conclusions}

Contrast enema findings do not correlate with the final effective enema in patients enrolled in our bowel management program. We recommend starting patients $\leqslant 30 \mathrm{~kg}$ on a saline enema volume of $20 \mathrm{~mL} / \mathrm{kg}$ and add irritants (soap) as needed. For patients $>30 \mathrm{~kg}$, we recommend arbitrarily starting at a $600 \mathrm{~mL}$ saline enema.

\section{Additional Information}

\section{Disclosures}

Human subjects: Consent was obtained by all participants in this study. University of Utah issued approval 74392. The project was approved by University of Utah IRB. Animal subjects: All authors have confirmed that this study did not involve animal subjects or tissue. Conflicts of interest: In compliance with the ICMJE uniform disclosure form, all authors declare the following: Payment/services info: All authors have declared that no financial support was received from any organization for the submitted work. Financial relationships: All authors have declared that they have no financial relationships at present or within the previous three years with any organizations that might have an interest in the submitted work. Other relationships: All authors have declared that there are no other relationships or activities that 


\section{Cureus}

could appear to have influenced the submitted work.

\section{References}

1. Derikx JP, De Backer A, van de Schoot L, et al.: Long-term functional sequelae of sacrococcygeal teratoma: a national study in the Netherlands. J Pediatr Surg. 2007, 42:11221126. 10.1016/j.jpedsurg.2007.01.050

2. Levitt MA, Dickie B, Peña A: The Hirschsprungs patient who is soiling after what was considered a "successful" pull-through. Semin Pediatr Surg. 2012, 21:344-353.

10.1053/j.sempedsurg.2012.07.009

3. Levitt MA, Peña A: Anorectal malformations. Orphanet J Rare Dis. 2007, 2:33. 10.1186/17501172-2-33

4. Vande Velde S, Van Biervliet S, Van Renterghem K, Van Laecke E, Hoebeke P, Van Winckel M: Achieving fecal continence in patients with spina bifida: a descriptive cohort study . J Urol. 2007, 178:2640-2644. 10.1016/j.juro.2007.07.060

5. Bischoff A, Levitt MA, Bauer C, Jackson L, Holder M, Peña A: Treatment of fecal incontinence with a comprehensive bowel management program. J Pediatr Surg. 2009, 44:1278-1283.

10.1016/j.jpedsurg.2009.02.047

6. Bischoff A, Levitt MA, Peña A: Bowel management for the treatment of pediatric fecal incontinence. Pediatr Surg Int. 2009, 25:1027-1042. 10.1007/s00383-009-2502-z

7. Levitt MA, Martin CA, Olesevich M, Bauer CL, Jackson LE, Peña A: Hirschsprung disease and fecal incontinence: diagnostic and management strategies. J Pediatr Surg. 2009, 44:271-277. 10.1016/j.jpedsurg.2008.10.053 